\title{
comparative analysis on corruption in Iran and Japan
}

\author{
Professor Dr. Sorush Niknamian \\ Board Member of Weston A Price Foundation, Washington DC, USA \\ Email: so.niknamian@gmail.com
}

\begin{abstract}
The corruption is a phenomenon with which some countries have been today grappled, especially developing nations. It has multiple causes and consequences and its range starts from an individual action (e.g. bribe) and covers all cornerstones of political and economic system and is developed. Despite complexity, difficulty and sensitivity of involvement with this symptom, the extensive studies have been conducted for measurement of corruption, expression of reasons for perpetration of such criminal activity and presentation of deterrent solutions by international communities during recent years. This study aims to conduct comparative analysis on corruption in Iran and Japan and the findings suggest that Iran has acquired rank 130 in received corruption while Japan received rank 74 in this regard.
\end{abstract}

Keywords: Iran, Japan, Economic, Comparative

\section{Introduction}

Arabic term 'فساد' (corruption) is derived from 'فسد' root and means prevention from doing of right and healthy action and in English language it is expressed by this term with Latin root that stands for 'corruption' and 'rumpere' and something which is broken or infringed and it may include laws and regulations or administrative rules. By this concept, corruption is any phenomenon that prevents a group of their goals and functions (Rahimian, 2014: Tanzie, 1999). There are various definitions for corruption. Robert B. Zoe-lick, chairman of World Bank, assumes economic corruption as a cancer that steals of poor people and consumes it in governmental and moral affairs and removes the trust.

In another position, corruption has been interpreted as power abuse for personal favor and it comprises of some issues e.g. bribe, fraudulence, hoarding and embezzlement etc. (Rahimian, 2014; Dipiyatza, 2008).

The corruption is not a new subject. One of the Indian authorities wrote a book about corruption 200 years ago. According to a definition proposed by Shcilfer and Shini, corruption means use of governmental properties for personal purpose. Concerning warning to treason to public property, Imam Ali (PBUH) has referred to Ziad Ibn Abih successor of Basra governor and implied: 
'Verily, I swear to God if it is reported to me that you have betrayed in public properties whether a little or lot I will treat you by difficulty so that you enjoy it a little and to become frustrated, inferior and wandered about cost of your wife.'

Therefore, in government of Imam Ali (PBUH) it has been highly emphasized in protection from public properties and non- abuse of financial and governmental facilities under any circumstances (Rahimian, 2014; Mehnatfar, 2008).

Importance of study on reasons of occurrence of corruption is further revealed by perceiving of damages and consequences of this phenomenon. In many developing nations, all people and non-governmental organizations and media believed in corruption as the only main factor under dominance of aliens and poor economic growth. Frisch Pillai (2004) argued that corruption was one of the factors and as one of the main barriers against development.

The financial corruption breaks the existing laws to provide for personal interests and profits. The corruption is often called as a serious disease. It is similar to a disease such as cancer and AIDS that is dastardly penetrated from one organization to another and or from an institute to another so that reduces power of all existing organizations until it is led to collapse of governing political system. For instance in Asian and African countries, prevalence of financial corruption has been assumed as one of the foremost barriers in the path of successful economic advancements. The high level of financial corruption may lead to inefficiency of governmental policies. The existing studies show that the corruption reduces investment and as a the consequence it will decrease economic growth. The financial corruption can lead economic activities from their productive form toward basement and hidden rents and activities and also it may create horrendous organizations e.g. Mafia. The extensive and pervasive corruption is one of the symptoms for weakness of governance and poor performance of the governance can reduce trend of economic growth and development (Rahimian, 2014; Mehnatfar, 2008).

\section{Types of economic corruption}

There are several forms of economic corruption that may be apparent and or hidden. The economic corruption may be committed for the sake of acquisition of personal interests and or based on spite. In any case, customer and consumer will pay for cost of economic corruption. The corruption quenches competition and inverts free market. The economic corruption includes various forms such as bribe, fraudulence, embezzlement and kickback and we will define each of them in the followings.

\section{2-1- Bribe}

The bribe is the most common type of business corruption. The bribe may occur between two persons or one person and a public organization. The bribe includes several types. 
Sometimes, it is called grease money. The personnel receive money from the opposite side before they undertake for a business or issue a permission (Segravs, 2012).

Regarding definition of bribe, Mohammad Jafar Jafari Langeroodi has mentioned: 'Bribe (punishment) is to give property to official or unofficial governmental or municipal officer to do a task out of administrative or judicial works albeit the given task is not related to occupation of receiver of that property whether s/he receives that property directly or by intermediation of another person. There is no difference if receiver of the given property is able to do the task for which s/he received the bribe or not and it is not different if doing of a task, which is stipulated to be implemented, is rightful and according to the law or not (Rahimian, 2014; Islampour Karimi, 2008).'

\section{2-2- Fraud}

Fraud is another type of economic corruption in which members of a company abuse it for their personal interests. This type of fraud is visible both in public and private sectors (Sgravz, 2012).

Fraud is to exploit from property of third party by means of deceptive tools and it is similar to theft and betrayal to the deposit in terms of dominance over assets of others but it has special features that isolate it from aforesaid crimes.

One of these features is to employ fraudulent tools, deceiving of victim of fraud and submission of his/ her property to the fraudulent party as the specific characteristic of fraud not existing in other crimes. Whereas the given crime takes place in various forms, the social developments may play efficient and direct role in changing of various fraudulent forms and it necessitates for paying more attention to the given points so that both to preserve rights of culprits and fraudulent sides not to be able to plunder their audiences by deceiving them (Rahimian. 2014).

\section{2-3- Embezzlement}

Extraction of commodities of the company for personal use is called embezzlement. The various persons, who can regulate the capital again and conceal this fact the capital has been lost, are violators (Segravs, 2012).

Embezzlement of public properties has been synchronously mentioned with establishment of government and it has the same history with the governments. Embezzlement is one of transgressions committed by governmental employees and personnel of public institutes and companies and or affiliates to the government and other officers to public services and it is committed against the properties belonging to the government or third parties and always assumed as a serious threat against government and nation. 
Seizure and possession of given property is deemed as criterion for realization of crime. The range of this crime can be extended to properties of private banks, non-governmental joint stock companies, parties, syndicates and also immoveable properties.

\section{2-4- Kickback}

In business, kickback denotes payments done by vendors and against the contracts that are led to over-inflation of cost for the dine work. If fact, it is a type of commission that is given to the bribe receiver against the service which may be returned (Segravs, 2012). Transparency International (TI) ${ }^{1}$ organization was established to fight against corruption. This organization holds a conference titled International Ant-Corruption Conference (IACC) once every two years. The first conference was held about fighting against corruption (1981) with the presence of 30 representatives from various world countries in USA and the tenth conference was also held (2001) with 160 agents from different nations of the world in Czech. The corruption index was published by Transparency International (TI) Organization in 1995 for the first time. This organization introduced and measured corruption index similar to other variable of economy. The Corruption Percentage Index (CPI) shows rate of corruption (0-10). Based on this index, zero value indicates the maximum corruption and 10 shows the minimum rate of corruption. For example, in 2010 Finland (9.9) was known as the cleanest country and Bangladesh (0.4) as the most corruptive among various countries in the world.

This organization (2007) has determined CPI for 180 countries in the world. Denmark, Finland and Singapore with score of 9.4 and CPI (1) versus the highest index (10) have witnessed the minimum corruption. Burma and Somalia had the lowest rank with numerical CPI of 179 and score of 1.4. Islamic Republic of Iran had numerical CPI 131 and score of 2.5 of 10. This index is not considered as a suitable parameter for Iran to achieve development designated by the government in twenty-year national outlook and it may be assumed as the basic factor in national economic growth and development. With numerical CPI of 172 and score of 1.8 of 10, Afghanistan is placed near Chad and Sudan in terms of this parameter. Tajikistan, Azerbaijan, Belarus, Kyrgyzstan, Liberia and Zimbabwe have numerical CPI of 150 so they lack suitable status.

Among countries in the Middle East, Qatar with CPI of 32 had the lowest corruption level and Iraq $(\mathrm{CPI}=178)$ has the highest financial and administrative corruption in economic field. ${ }^{2}$

\footnotetext{
1 - For more information, see also www.transparency.

2 - Among other nations in the Middle East, UAE (34), Bahrain (46), Oman (53), Jordon (53), Kuwait (60), Saudi Arabia (79), Lebanon (99), Iran (131), Yemen (131), Libya (131), Syria (138), and Iraq (178) have the lower ranks. The transparent countries e.g. Switzerland (7), Canada (9), Britain (12), Germany (16), Japan (17), France (19), USA (20), Turkey (64), China (72), India (72) and Russia (143) have allocated these ranks.
} 
Based on reports of World Bank (1990), so far several books and papers have been published about corruption in 44 different international languages throughout the world among of which 50\% were in English, $13 \%$ in French, $11 \%$ in Spanish, $5^{\wedge}$ in Chinese and $17 \%$ in other world languages. Today, more than 14 different international centers deal with gathering of different information regarding calculation of CPI.

CPI index indicates corruption presentation side. Accordingly, Transparency International Organization (1999) has introduced another index called Bride Payer index (BPI) by review on 19 countries. As it revealed from title of this index, it is designated for bribe-payers. Unlike CPI, PBI index measures corruption applicant side. The related important point is the size of corruption. In other words, it does not consider the present corruption. According to attitude of some economists, corruption exists in all countries but corruption level is different among the countries. The numerical values of these indices also show totally the corruption level and size. The corruption degree has been defined as a cancer for the nations if it is postponed it can penetrate into all dimensions as a systematic phenomenon so that it is impossible to fight against it.

Table (1) shows CPI and BPI for 21 countries from 1999 to 2002. In 1999, three countries i.e. Sweden, Canada and Singapore (2.4, 1.9 and 9.9) have devoted title of the cleanest countries between 21 nations and Russia (2.4) had the last position among 21 countries. In 2000, three countries i.e. Singapore, Sweden and Canada were ranked as the first to third positions of the cleanest nations between the studied countries and similar to the former period Russia (2.3) has been introduced with the highest corruption in terms of CPI index. On the other hand, BPI indicated Sweden, Australia, Canada, Switzerland and Austria as the cleanest countries of the world and it shows again the highest rate of corruption in Russia. Thus, it is seen the corruption can be measured and calculated in terms of two supply and demand approaches (CPI and BPI) and variable of corruption enters into computations and analyses in many economic studies as a quantitative variable. In other words, corruption is not assumed as a qualitative variable today but based on designated techniques of Transparency International Organization, it has been converted into quantitative variable.

Table 1: CPI and BPI indices for various world countries

\begin{tabular}{|c|c|c|c|c|}
\hline Name of country & BPI 1999 & BPI 2002 & CPI 1999 & CPI 2001 \\
\hline Sweden & 8.3 & 8.4 & 9.4 & 9 \\
\hline Australia & 8.1 & 8.5 & 8.7 & 8.9 \\
\hline Canada & 8.1 & 8.1 & 9.2 & 8.9 \\
\hline Austria & 7.8 & 8.2 & 7.6 & 7.8 \\
\hline Switzerland & 7.7 & 8.4 & 8.9 & 8.4 \\
\hline Netherland & 7.8 & 7.8 & 9 & 8.8 \\
\hline UK & 7.2 & 6.9 & 8.6 & 8.3 \\
\hline Belgium & 6.9 & 7.8 & 5.3 & 6.6 \\
\hline Germany & 6.2 & 6.3 & 8 & 7.4 \\
\hline USA & 6.2 & 5.3 & 7.5 & 7.6 \\
\hline Singapore & 5.7 & 6.3 & 9.1 & 9.2 \\
\hline
\end{tabular}




\begin{tabular}{|c|c|c|c|c|}
\hline Spain & 5.3 & 5.8 & 6.6 & 6.7 \\
\hline France & 5.2 & 5.5 & 6.6 & 6.7 \\
\hline Japan & 5.1 & 5.3 & 6 & 7.1 \\
\hline Malaysia & 3.9 & 3.4 & 5.1 & 5 \\
\hline Italy & 3.7 & 1.4 & 4.7 & 5.5 \\
\hline Taiwan & 3.5 & 3.8 & 5.6 & 5.9 \\
\hline South Korea & 3.4 & 3.9 & 3.8 & 4.2 \\
\hline China & 3.1 & 3.5 & 3.4 & 3.5 \\
\hline Hong Kong & - & 3.4 & 7.7 & 7.9 \\
\hline Russia & - & 3.2 & 2.4 & 2.3 \\
\hline
\end{tabular}

Source: www.transparency.or

In the latest report from Transparency International Organization about perceived corruption index, Iran has promoted one step compared to the last year and placed at rank 130 (between the given countries) (ICC News Agency, March 2018).

The Transparency International Organization as NGO published the latest report about perceive corruption index in various countries of the world based on data in 2017. It is a report that indicates that most of world countries have not progressed in the reducing of corruption and or experienced very little progress.

The Transparency International Organization ranks countries according to Corruption Perception Index and based on the given polling by experts and actors of business field about rate of corruption in public sector of the given country. in the latest report, this organization has analyzed 180 countries from this perspective. The corruption perception index varies from 0 to 100; in other words, the score of the most corruptive governments (according to attitude of business experts and owners in the given country) is close to zero and also the cleanest governments have score closer to 100 .

The governments of developing nations should implement comprehensive and purposive plans to fight against corruption, but they also need to emergent aids in response to national strategies for fighting against corruption.

Any support is made by international cooperation and support. The assistant countries and international financial institutes should stop their financial aids that may cause corruption in governments and they should publish names of international enterprises that pay bribe in the world.

Today this index expresses this point that it is not only seen in poor countries where corruption is highly exacerbated, but the corruption level is also very concerning and dramatic in some European countries e.g. Greece and Italy and in countries with a lot of oil deposits such as Nigeria, Angola, Azerbaijan, Indonesia, Kazakhstan, Libya, Venezuela and Iraq.

In order to change this status to share ordinary people in oil wealth of their countries, this organization along with NGOs has asked all international oil companies to publish kickbacks 
to the governments and public oil companies. This will enable citizens and organizations of civil society in Nigeria, Angola, Iraq, Indonesia and Kazakhstan to have more transparent image of governmental revenues so that they can audit their governments where the governmental budgets are not spent and they disappear instead and to move them toward high-cost projects without return and the hidden accounts of politicians and or public officials in optimization of rare sources.

Iran has been never able to achieve score higher than 30 and rank better than 120 in terms of CPI index in recent years (ICC News Agency, March 2017) while Japan has obtained tank of 74 similar to UK.

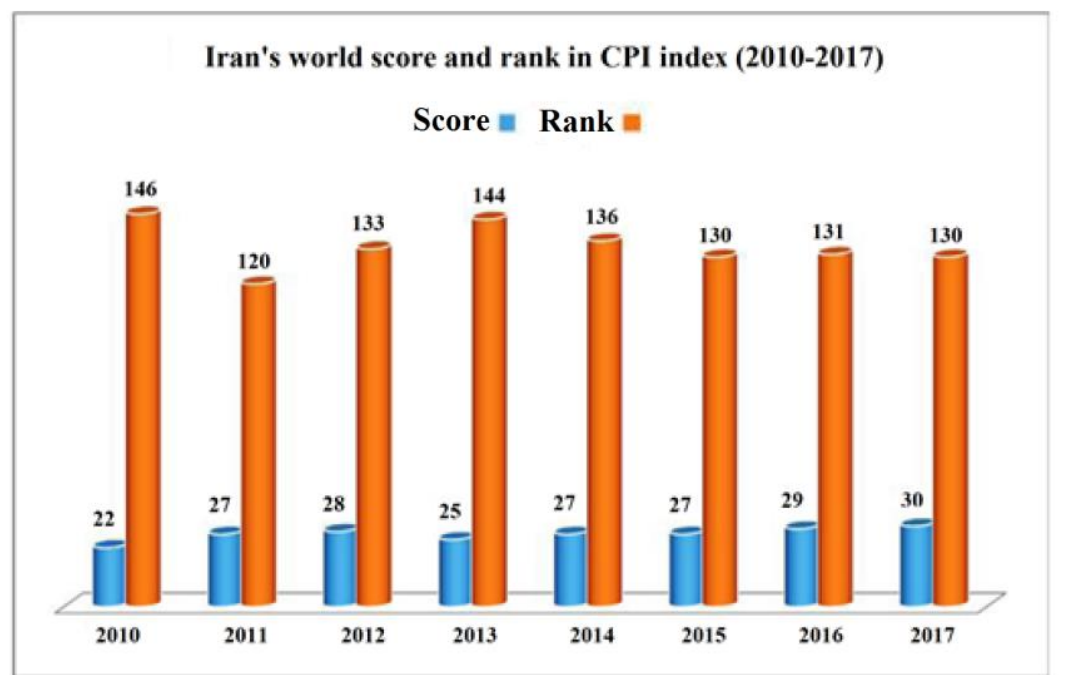

In terms of regional position for CPI index, score and rank of Iran is never reasonable so that among the countries in the Middle East, only Lebanon, Iraq, Yemen and Syria have obtained lower ranks than Iran in ranking system of Transparency International Organization. Concerning CPI index, UAE, Qatar and Cyprus have the best position in this region.

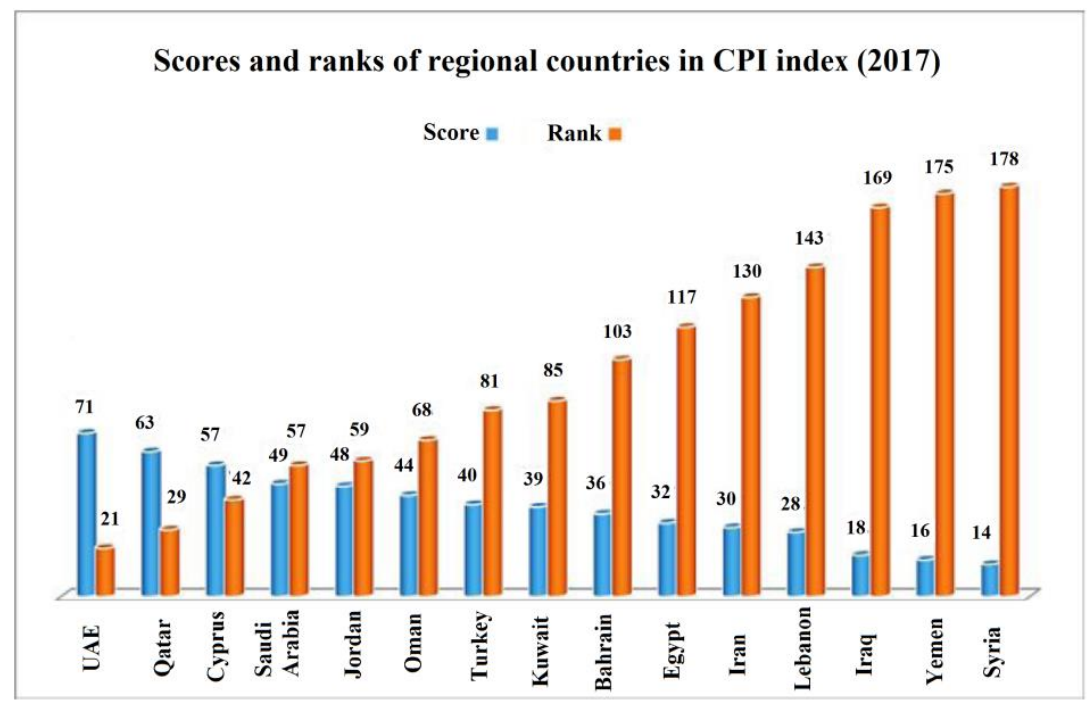


As it also seen in most of important economic and welfare indices, four Scandinavian countries (Denmark, Finland, Norway and Sweden) are placed between the 10 superior countries of the world in ranking of CPI index as well; although, New Zealand could achieve the first world rank and higher than all these countries. In addition to the aforesaid countries, names of other countries are also visible in group of superior countries e.g. Switzerland, Singapore, Canada, Luxemburg, Netherland and UK.

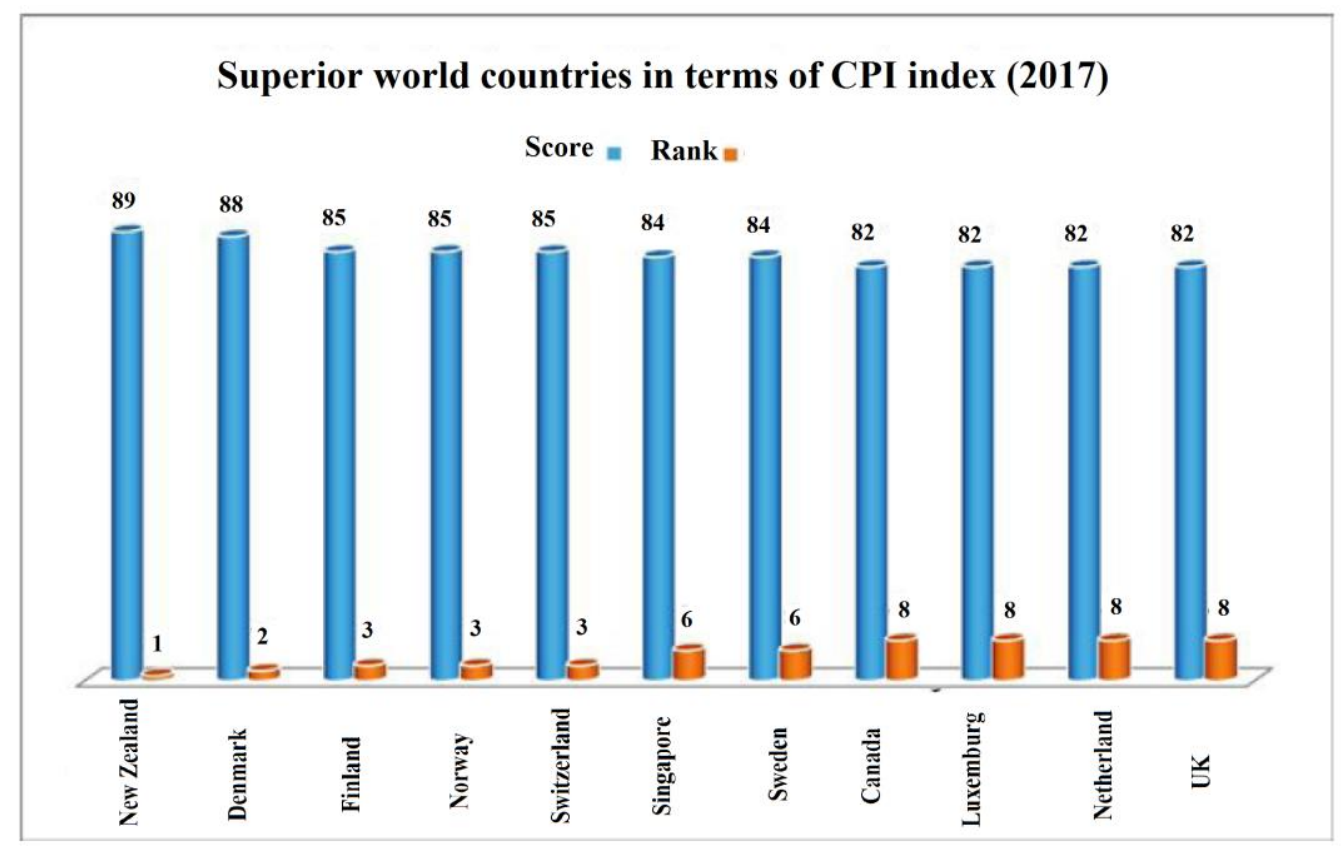

\section{2-5- The reasons for creation of corruption in Iran}

1. The presence of rent in an economy is a plausible reason for creating of corruption. Due to existing huge oil reserves and prosperous revenues of this divine gift in Iran, various rents are created for different groups in some cases they are led to corruption from different aspects. The monopoly of market, competitive system and lack of transparency of information may also create rent for those who have access to certain information.

2. Public economy of Iran and great size of government are also considered as the major factors for creating of corruption because wide and extensive governmental bureaucracy and lack of deregulation for embarrassing rules during recent decades has made private sector or even the public sector for circumlocution of law despite the existing technological growth and lays foundation for corruption.

The foremost reasons for economic corruption in economic sector is related to governmental incumbencies in economy and it includes trade restrictions, industrial subsides, control of prices, multiple exchange rates, low wages in public and trading services and natural resource reserves e.g. petroleum. The economic corruption reduces investment and slow economic growth and finally it is led objectives of economic development not to be realized in the 
country. the tax revenues are reduced and quality is decreased in economic infrastructures and public services.

The presence of extensive public sector is one of the major problems in Iranian economy and the main factor in formation of economic corruption in the country. Presently, despite notification of policies of Article 44, many companies, institutes, and organization and industries that have been formed by virtue of this article are not only prepared for equalization of their structure, but in many cases they have developed their exclusive power in a market compared to other market. Therefore, under such circumstances a condition may take place that the major amounts of national resources can be abused and allocated by governmental canals because of presence of influential directors.

3. During recent decades, inappropriate privatization and liquidation of subsidies in cash could be the origins for corruption in Iran in recent years.

4. Inappropriate control of prices caused by political or economic reasons during some recent decades and keeping the prices of goods or services smaller than the market value that may act as the source of rent and rent-seeking for specific persons or groups that want to continue this trend even by bribing.

5. Lack of financial discipline, ordered economy, commercial and exchange limits and rationing, multiple exchange rates and non-competitive and decentralized banking system are considered as main centers for creating of monetary- banking corruption.

6. Weakness of mass media and lack of responsive and regulatory spirit between directors because of their high power may also lead to duration of corruption on various scenes.

7. Sociological factors e.g. spirit of rent-seeking in a community, tendency of influential persons and governmental authorities to hiring of their own relatives and friends, classification of society based on unconventional parameters (fractional ethnic, lingual and religious) and exemplar different behavior with corruptive subjects may play role in creating of economic corruption.

8. Poor meritocracy based on science and expertise in appointment of CEOs in organizations and ministries can be also effective because corruption may be due to incompetency of a director in administration of system under his/ her supervision.

9. One of the other major reasons in formation of economic corruption is the existing of revenues resulting from oil sale in the previous years and decades that included the great part of national resources of Iran. The oil wealth has created new profitable opportunities and injected credit sources into various economic sectors within framework of development plans where this has generated lucrative opportunities. Alternately, focusing of power in Iran causes forming of beneficiary groups around a centralized power core because of the same 
bureaucratic structure in the government. Therefore, the mutual effect of these two forces causes national economic directors to discover the existing opportunities instead of relying on creativity and entrepreneurship. The social and familial relations are crucially important in developing countries e.g. Iran and they are known as so-called 'warm communities'. In these communities, any individual shall help his/ her relatives and friends as possible. In contrast, any person relies on assistance of his/ her relatives and friends to achieve personal goals and to solve the given problems at first place. Under such ties, it is natural for a governmental employee or official to feel that s/he is tasked with using from his/ her occupational powers to assist the friends and relatives.

10. The basement economy is one of the other important factor. Due to existing suitable technologies in various transactional fields in goods, money and capital market in the advanced countries, the information about size of economic tradeoffs is relatively precise and there is not a lot of problem in this regard. However in developing nations e.g. Iran, the excessive growth of servicing sector and thus basement economy has reduced the national controls. Through such a climate, some items and concepts are formed e.g. tax escape, smuggling of goods and fake products etc. Although phenomenon of black market and trafficking of goods have been always assumed as examples of economic corruption and bribery and usury were blamed from very long time ago, the scope of such activities has become wider by rising of power extent so that in those countries which could not meet public opinions this trend may remove influence of certain classes in enjoyment of facilities and conditions of transparent activities. Therefore, it is necessary to recognize position of Iran as a developing country in parameters of economic transparency because emphasis of all high ranking officials in Iran on economic health shows that economic health has not yet obtained in Iran despite all conducted efforts.

11. The structural and organizational problems for fighting against economic corruption is also one of the other reasons for spreading of economic corruption.; In other words, rising number of regulatory organizations e.g. supreme administrative court and audit organization and Ministry of Intelligence etc. and governmental bodies regardless of evaluation of productivity of these references causes only to spend public budgets and no clear report is obtained of these activities.

The existing evidences suggest that 14 references are tasked directly and indirectly with supervision to fight against economic corruption inside administrative structure of the government.

12. The bureaucracy governing over judiciary system and lack of necessary serious behavior for fighting against economic corruption is led to failure of the formed cases as if type of unseen immunity is designated for the violator officials in economic and financial crimes so that despite proposing of more than 64 cases about perpetration of crime by high-ranking 
directors during recent years fewer numbers of them have not yet reached to process of issuing of final award in the judiciary system.

13. Oil and corruption: Oil revenues are the major source of income in Iran (Kashfi, 2016). The oil has played essential role in spreading of corruption and despotism in Iran (Keshmiripour, 2015). There is relationship among oil price and corruption in Iran (Khoshchehreh, 2017). The great amounts of governmental revenues by sale of oil products have caused the productive activities and free competition to be turned into minor subjects in Iran (ICC News Agency, March 2018).

\section{2-6- Effects of corruption:}

Spreading of corruption Iran, especially organized corruption, has put the governmental policies as contradictory to the interests of majority and thereby it has led to reducing effectiveness of governments to lead the activities. As a result, it has decreased public trust in governmental and non-governmental bodies and caused prevalence of indifference, laziness and inadequacy throughout the society (Tehrani, 2015). According to the report of strategic studies office of IRI Presidency, the rate of trust has reached to $10 \%$ among members of Iranian community and index of honesty and integrity is close to 8 percent; namely, the community has suffered from serious moral collapse (Nikahang, 2016).

The excessively governmental economy of Iran could not be coordinated with private and cooperative sectors as it predicted in the constitution and not only the cooperatives have not grown duly in practice, but privatization was also misled and the economic sanctions and embargoes immediately became as pretexts to remain these two factors to be silent and instead the trend started to look for strategies to circumvention the sanctions. However they were followed by some seemingly benevolent objectives but in fact as a unique opportunity was provided for ret-seeking, official smuggling, embezzlement and bribery in the worn body of governmental economy. It was here that inefficiency of Iranian economy was revealed further and hasty entry of owners of political power into the damaged trade market also worsened this condition to the extent that some news is frequently heard about financial abuse, embezzlement or briberies and it seems national mind has been also accustomed to hearing of it (Berahmandi, 2014).

\section{Corruption in Japan}

Under some conditions Japan has stabilized its position as one of the economic powers in the world while it is under very unfavorable conditions in terms of possession of natural resources as well as political fate. This country possesses very limited natural resources and most of isles and major part of soil are of mountainous and volcanic type. Politically, the defeat of this country during World War II was also followed by regretful fate for this country. after defeat in this war, Japan exercised very high economic austerity conditions with over 13 million unemployed persons. The shortage of foods and inflation rate was very 
high to the extent that salaries of individual were not sufficient to meet their nutritional requirements. Formation of black market was only some part of problems in this country. these problems plus necessity for reconstruction of the country caused by war destructions were led to ruining of $25 \%$ of non-military assets as well as $41.5 \%$ of national wealth in this country and also the liability for payment of war compensation to the Axis Powers had caused exertion of higher pressure to this people and Japanese government; but by taking logical approach that is highly similar to resistive economic plans at least in terms of improvement of national product and through cooperation with each other, the Japanese people and government converted the poor and demolished Japan into one of the economic and production powers in the world. Japan was turned into one of the major pioneers in world industry and technology through cooperation f government and people and industry and also by development of high technologies (Naghizadeh, 20130.

\section{3-1- Governmental production- centered economic policies}

However the governmental policies of this country have acted as the best supplement for strong economic culture of Japanese people during decades of their advancement these were policies that led to upgrading of knowledge and technology and finally high growth of national product in this country (Naghizadeh, 2013).

\section{3-2- Strong production culture}

The high production culture is one of the amazing progressive factors of Japanese national economic product among people of this country.

During these decades, Japanese people not only produced for profit, but they considered production and work as holy and valuable task. Likewise, Japanese people made efforts for upgrading of their productivity and efficiency. They curiously followed more suitable skills and techniques for working an production. In fact, the motivation of Japanese workforce for improvement of their efficiency was implemented endogenously and or by personal motives rather than being influenced by motivational economic system. Attaching importance for work and production, double efforts and also trying for upgrading of knowledge and skill are deemed as three important characteristics of Japanese workforce (Naghizadeh, 2013).

\section{3-3- Proper consumption culture}

Along with high level production culture, proper consumption culture was also one of the key factors for economic advancement of Japan during decades after World War II. Two important characteristics of Japanese people in consumption field included frugality and moderation in consumption and emphasis in consuming of Japanese made products (Naghizadeh, 2013). 
The Japanese people have been well-known for their frugality during these years and they have regulated and controlled their consumption proportional to national economic conditions. The same frugality that means differently avoidance from profligacy and lavishness has caused accumulation of more capital and thus providing of financial sources to improve national product in this country (Naghgizadeh, 2013).

Likewise, emphasis of Japanese people in consuming of domestic products during the early decades after Great War for improvement of domestic industries is assumed as an important point in economic advancement of this country. this cultural background caused the government to implement successfully policy for reduction of imports from other countries to improve domestic industries in Japan; it was a policy which sometime assumed so extremist that has been implied as isolationist policy. Procure of domestic market for Japanese products and goods are considered as an important supporting point for improvement of national product in Japanese (Naghizadeh, 2013).

\section{3-4- The Japanese companies as rivals for American Enterprises}

After independence, Japan could convert this country quickly into an economic superpower. In 1980, more than $80 \%$ of Japanese growth was due to rise of exports of which the major part was mainly to USA. The Japanese companies had overtaken to their American rivals inside USA. Finally, rise of Japanese economic trade balance versus USA was led to emerging of conflicts and pressures exerted by USA to restrict exports. The USA pressures compelled Japanese government to encourage people toward American commodities and to reduce USD value versus Japanese yen in order to make American goods cheaper but with their high slyness Japanese people have used cheapness of American goods and bought some of strategic real estates in USA! Along with commercial policy in coordination with improvement of national product, financial and banking policy of this country also provided adequate financial and capital sources for Japanese producers. In line with spirit and culture of moderation in consumption and saving of Japanese people the accumulation of small capitals and allocation of facilities to the producers were assumed as impetus for industry and technology in this country (Naghizadeh, 2013).

\section{3-5- Strong production culture}

Strong production culture is one of the marvelous progressive factors for Japanese national economic product in people of this country. During these decades, Japanese people not only produced for profit, but assumed production and working as sacred and precious activity. At the same time, Japanese people tried for upgrading of their productivity and efficiency. They curiously followed more suitable skills and techniques for working an production. In fact, the motivation of Japanese workforce for improvement of their efficiency was implemented endogenously and or by personal motives rather than being influenced by motivational economic system. Attaching importance for work and production, double efforts and also 
trying for upgrading of knowledge and skill are deemed as three important characteristics of Japanese workforce (Naghizadeh, 2013).

\section{3-6- Public trust as development factor in Japan}

The public trust is cornerstone and permanent source of development not natural resources in several continents. It was not passed very long time after entry into Japan at early 1970s and the first oil crisis that Japanese newspapers informed that the current prime minister of this country has received bribe from a manufacturer of a foreign passenger airplane (Lockheed) to recommend that type of airplane to Japanese Civil Aviation Organization. After a few days, officers of judicial police entered office of prime minister and arrested him before photographic and TV cameras and flashes and it was led him to resign from the job and after trial he was sentenced to imprisonment. There is no doubt in a country where it is fight against financial corruption at macro level at the top of government the public trust in work and effort is turned into ideological and faith-based process. Therefore, mobilization of active forces is an easy task for inclusive and constant national development and it leads intellectual- cultural foundations for development because the agents of financial corruptions are not mentioned in media by their alias and abbreviated names. The Japanese government relies on everlasting origin of diligent and disciplined human sources and national trust. Therefore, locomotive of national development is stable and not stopped despite over a half century of struggle and battle with neighbors and world superpower e.g. Russia and USA and all natural disasters and lack of natural resources. There are also some other various parameter to attract public trust in government. One of them is tangible economic development (not exportation of national wealth) that affects level of incomes and low rate of unemployment. In Japanese law, the bribery is found very rarely about public and private officials. Among Asian countries, Japan has the least rate of corruption in 2017. According to Article 197 of Japanese Punishment Act, giving bribe to any governmental officer is prohibited (Yoshida, 2018).

Trust may be assumed as a relative concept because trust depends on this point how much an individual assumes another person as trustworthy and this depends on individual attitude (Midha, 2012).

Five dimensions are usually designated for trust. These dimensions include honesty (righteousness, purity and verity), competency (to have skill and knowledge in technical field and humanitarian relations), stability or consistency (potential for prediction and good judgment when being exposed to various circumstances and conditions), loyalty (face-saving and prestige), sincerity (exchange and giving of information freely) (Mannemar et al., 2017). It seems the honesty is the foremost dimension among aforesaid dimensions since someone does not assume spirituality and honesty for the other individual other dimensions will lose their real meaning and concept (Robbins, 2009). 
The organizational trust can be assumed as one of the important elements in organizational social capital that is proposed as facilitator and link for social relations. Trust is considered as wide knowledge that covers important concept for study because one can coordinate human behaviors by trust.

According to Bordeaux (1986) social networks are not natural gifts and they should be created by doing of logical and purposive actions to achieve other capitals and resources. Bordeaux argued that it is impossible to perceive social world without perceiving of role of various capital forms and not only that form of capital mentioned in economic theory.

Putnam (2000) believes that social trust does not emerge in solid and inflexible classes in communities. He claims the great inequalities in wealth of so city are hazardous for development of partnerships and correlations.

Based on attitude of Giddens (1998), trust is immediately related to concept of structure and institution; on the one hand, and characteristic of modern community, on the other hand. In his opinion, structure is described according to recursive rules and sources. The recursive feature and continuity are the same elements he also employed them in definition of trust. Based on approach of Giddens, trust is the expectation for fulfilling of wishes about probable events.

The studies done by Lynden JL and Klingle (2014) indicate that the trust creates intrapersonal and interpersonal effects and influences in intra- and extraorganizational relations. Thus it is implied that the higher organizational trust is followed by improvement of job satisfaction,. Organizational commitment in trust climate between personnel, rise of cooperation and consultation, division of information for problem solving, facilitation for empowerment, ability for change, organizational learning and innovation, reduced spiritual and mental stress, decrease in lack of confidence to the future, solving of conflicts and final creating of a framework for rise of organizational productivity. On the other hand, lower interorganizational trust will be typically accompanied with rise of conflict, organizational instability, leaving of services, reduced motivation, rumors of unresolved strikes, and creation of barrier against path of realization of organizational goals etc. It is believed in social trust that the majority of individuals among them relationship is potentially established will behave marvelously.

Disclosure of corruption in governmental authorities and directors in Japan was exposed extremely with public opinion to the extent the related official is never inclined in acceptance of the adverse effect of this crime and these individuals issue the judgment for their own and in addition to resignation and excuse in some cases they assume suicide as the last resort to escape from fiasco (Japanese Law, 2010).

The Japanese Punishment Act has prohibited kickbacks for facilities. The moral law determines some constraints for giving gift that should be recorded and the governmental 
middle-age and older officials should declare if they needed to more than 50000 Euros. Payment of gifts and facilities is not common in practice (Teishi, 2013).

\section{3-7- Judicial system}

The corruption is found very rarely in Japanese judicial system. The judicial independence is respected in practice. The courts act fairly and rule of law has been well established. The companies report that informal payments take place rarely in the court. The legal system is effective in resolving of differences and challenging regulations in businesses. The implementation of contract is averagely done for 360 days which are lesser than in other OECD countries (Park, 2017).

\section{3-8- Police}

No case of corruption has been reported in Japanese police force. The government adapts efficient mechanisms for review and punishment of abuse and corruption.

\section{3-9- Public services}

The rate of risk for presence of corruption and bribery is very low in enterprises upon receiving license and other public services in Japan. The Japan is placed among the countries where the rate of informal payments and bribery is at minimum level relating to public services. The enterprise should notice that Japan possess some regulations that increase costs of their business. The foreign and national investor can consult with governmental website to acquire information about commissioning of business in Japan (Park, 2018).

\section{3-10- Land administration}

No case of administrative corruption has reported in Japan. The copyright is one of the best protective rights in the world (Japanese Judiciary Website). Enrollment of properties lasts

for 13 days in average while treatment with license of quantitative construction is longer than average time in OECD but at lower cost.

\section{3-11- Tax administration}

Kickbacks and irregular briberies are very rare. As companies pay tax (Japanese Judiciary Website), CEOs have 330h deadline to make this process transparent.

\section{3-12- Custom office}

The risk of corruption is very low in Japanese border during importation and exportation of commodities. The frontier government is transparent and efficient; tariffs and non-tariff barriers and methods for a lot of imports are followed by high sensitivity (Latham \& Watkins, 2018). 


\section{3-13- Public provisions}

Administrative corruption, especially account settlement is very critical in Japan. The Japanese companies, politicians, governments, organizations and universities are closely related to each other and there is good behavior among stockholders (Latham \& Watkins, 2018).

\section{3-14- Natural resources}

There is no risk of corruption for active companies in natural resources sector in Japan (Park, 2018).

\section{3-15- Legislation}

The Japanese Punishment Act and law regarding prevention from unfair competition are included in anti-corruption laws. There is strong legal framework (Park, 2018).

\section{3-16- Political}

The power of emperor is limited and it is mainly restricted to formality task; although, he act as a real president in diplomatic affairs. The government is composed of executive, legislative and judiciary branches and there is difference over power among them. The executive power is granted to prime minister as head of government in the cabinet. The legal power is devoted to national regime. There are two parliaments. One includes parliament of representatives with 480 chairs and the other is the consultative parliament with 242 chairs. The rightist liberal democratic party kept the maximum number of chairs in parliamentary election in October 2017. Their leader, Shinzo Abe, remained as prime minister (Kochi et al., 2012).

\section{3-17- Regional and international issues}

Japan is a member in G7, G20, APEC, and ASEAN +3 and the strong supporter for the existing system based on international laws. The Japan has close relations with USA. USA has remarkable military troops stationed in Japan and it is undertaken for guarantee of security in Japan. President Trump extended this obligation during his trip to Japan at the end of 2017 (Park, 2018).

\section{4- Anti-corruption techniques}

Given that corruption has become organized and spread and complicated in Iran, the judiciary spokesman assumes intelligent, security and political measures as the anti-corruption solution and he considers reduced friction among people and governmental system the corruptive bureaucracy governing over the organizations such and taxation affairs administration, municipality and social security organization as the reason for decrease of public dissatisfaction (Tabibian, 2016). 
Several conditions should be fulfilled to fight against corruption in Iran: Resolute will, accurate computation and audit, possession of a comprehensive model for administration of community, absolute execution with no minimum negligence, and acceptance of the related pain (Rafipour, 2007). He has proposed some solutions to reduce corruption including: 1Prevention from promotion and display of wealth, 2- Encouraging for practical work and spreading of techno-vocational training and reduction of value of theoretical degrees, 3Cancellation of coordinative payments system law that has been led to excessive tendency to educational degrees and growing of institutes that produce educational degree, 4- Revision in national budgeting system in which it is encouraged for buying of equipment and salaries of personnel are kept at low level, and 5- Increasing for payment of salaries of controlling personnel more than their needs to avoid from their avarice.

\section{5- Background}

In a survey, Abbaszadeh Vaghefi et al. (2017) examined for recognition of local reasons that cause occurrence of administrative corruption (Case study: Municipality) in Tehran and the findings suggested all of extracted factors from qualitative phase were identified as effective reasons in occurrence of corruption in Tehran Municipality according to attitude of respondents in statistical sample. The results of ranking of reasons for occurrence of administrative corruption in Tehran municipality showed that among three effective organizational, personal and environmental factors in occurrence of administrative corruption, the personal factors were as the first priority and organizational factors and environmental factors were ranked at second and third priorities, respectively.

In their paper titled 'effective factors on administrative corruption and method of fighting against it' and by using of TOPSIS technique, Sorayaei et al. (2015) expressed that as the macro concept, administrative corruption denotes a group of behaviors of that class of personnel in public sector in which they ignore the accepted norms and laws to provide for their personal requests. This study has initially defined corruption, especially administrative corruption as the main barrier against development and the source for other types of corruption and then expressed the effective reasons and factors in administrative corruption and at the end implied the consequences and methods of fighting against this phenomenon. After extraction of the proposed parameters by Transparency International Organization and by using of TOPSIS technique, this study has ranked the countries of the world in terms of payment of bribe and embezzlement. The results of study suggest that there is a lot of difference between world countries in terms of administrative corruption among them Denmark is the healthiest nation and Somalia is the most corruptive country in payment of bribe and embezzlement.

In their paper under title of 'Effect of geographic situation of frontier cities on administrative health' (Case study: governmental offices in Sistan region), Karimian et al. (2014) expressed that neighborhood to countries e.g. Afghanistan and Pakistan, which are ranked at the last 
levels in terms of development in the world has caused a lot of problems for the Iranian frontier regions, especially Sistan and Baluchistan Province. In communities where political structure is centralized and governmental power has been deep-rooted in all sectors, doing of any activity is only possible by passing through the governmental canal and the main cue of all activities is at disposal of government and related personnel; as a result, the rate of exposure of clienteles with governmental references is naturally increased and the same rising demand by people and shortage of resources and facilities by the government prepares the ground more for increase of administrative corruption. It has been tried in this study to determine role and effect of environmental- geographical factors in administrative health of frontier cities. For this purpose, administrative health factors including (supervision and assessment, recovery of assets, anti-corruption law, enhancement of awareness, and institutionalization) were examined and prioritized based on order preference and using of questionnaire and TOPSIS model between administrative experts. The results of studies suggest inappropriate status of administrative health parameters in the studied departments. In fact, as the distance is increased further from the center by dispersion of governmental offices in cities of Sistan region, the rate of supervision and assessments is decreased and also probability of administrative corruption is also increased. This has proposed necessity for paying attention to approach of urban good governance as the lowest cost and most stable method for administration of complex and multilevel administration system in cities.

In his paper titled 'Analysis of effect of religious beliefs in prevention from administrative corruption', Samani (2013) expressed that whereas administrative corruption is one of the disadvantages of organizational community at present, this paper analyzes how religious teachings and especially prayer affects negative organizational phenomenon. This paper has been proposed by means of descriptive-surveying method and by choosing of 178 personnel of Iran Telecommunication Company based on administrative corruption model defined in Convention for Prevention from Administrative Corruption (approved in 2003) to discuss about this subject and analyze thoroughly using of a questionnaire to measure effect of religious tendencies on prevention from administrative corruption. Data analysis, which has been done by the aid of Pearson's test and regression, confirms the existing preventive effect of religious tendencies on all dimensions of administrative corruption.

Diment Tosatoo (2017) has looked for reasons and consequences of administrative corruption in a study by review of the conducted researches during recent decades and analyzed the existing knowledge about causes of administrative corruption as follows: The bureaucracy and political and administrative structure (the additional administrative bureaucracy and inefficient administrative- political structure might lead to spreading of administrative corruption), civil partnership and media freedom. As civil partnership and media freedom are at lower level, the administrative corruption is visible at higher level. 


\section{5- Conclusion}

What it can be imagined for increase and presence of corruption with all related cornerstones and dimensions in current world are activities of government and executive systems in economic activities such as subjects of taxes and custom levies and or implementation of national projects by government in the country and absence of transparent and simple laws concerning regulation of activities of private sector and complexity of these laws. It seems in economic sector ... that is an example for creation of rent and economic corruption, it is considered as a very important problem in economy of the countries and especially our Iran.

The governmental nature of Iranian economy and great size of government, huge oil reserves, inappropriate privatization and liquidation of subsidies in cash during recent years, absence of financial discipline, ordered economy, trade and exchange constraints and rationing, weakness of mass media and lack of responsiveness and regulatory spirit among directors, weakness of knowledge- and expertise-based meritocracy in election of CEOs in organizations and ministries, structural and organizational problems for fighting against

economic corruption are also assumed as one of the other reasons for spreading of economic corruption. In other words, rising number of regulatory institutes e.g. justice administrative court and audit organization and Ministry of Intelligence etc. and governmental systems without assessment of productivity of these references causes only spending of public budgets while no clear report is obtained from these activities. The existing evidences suggest that 14 references are tasked with direct and indirect supervision in fighting against economic corruption inside the administrative structure of the government. The bureaucracy governing over judicial system and lack of necessary absolute behavior for fighting against economic corruption is led to failure of the given files and cases as if type of unseen immunity is designated for the violator officials against economic and financial crimes. Under the conditions Japan has established its position as one of the world economic superpowers while is has not been under very favorable conditions in terms of possession of natural resources as well as political fate. This country has very limited natural resources and most of isles and major part of this soil are mountainous and volcanic. Also politically defeat of this country in World War II was followed by regretful status for this country. after defeat in this war, Japan exercised very hard economic conditions with over 13 million unemployed people. Shortage of foods and very high inflation rate were so serious that the salaries of people were not sufficient to provide foods for them and formation of black market was only one of the problems in this country. these problems plus necessity for reconstruction of country caused by war damages were led to destruction of $25 \%$ of non-military assets and ruining of $41.5 \%$ of national wealth in this country and also the liability for payment of compensation to Axis Powers was led to exertion of more pressure to Japanese people and government, but the Japanese people and government converted poor and ruined Japan into one of the economic and productive world superpowers by taking logical approach at least toward improvement of national product that was very similar to resistive economic plans and through cooperation 
with each other. Japan was turned into one of the major pioneers in world industry and technology by cooperation among government and people and industry as well as by developing of high technologies (Naghizadeh, 2013).

\section{References and sources:}

-Islampour Karimi, Askar (2008). Bribery, the ominous social phenomenon, Mobaleghan (promoters) scientific-News journal, vol. ?, p 109.

- Berahmandi, Bijan (2014). Fighting against corruption, or in Iran, is it the code name for political competitions?. Persian website of French International Radio, Sunday, 14 ${ }^{\text {th }}$ December 2014.

-Tanzie, Vito (1999). Problem of corruption, governmental activities and free market. Transl. Bahman Aghayee, Journal of political- economic information, vols. $149 \& 150$.

-Sorayaei, Ali, Gholamalipour Niazi, Musa Karim Nejad Bayee, Faezeh \& Jafari Lahijani, Fatemeh (2015). The effective factors on administrative corruption and the methods of fighting against it using TOPSIS technique. International Conference on modern approaches in management sciences, economy and accounting.

- Hassanzadeh, Mehdi, Shahbazi Koutanaei Iman (2014). Presentation of a model of effect of E-government on control of administrative and financial corruption in municipalities. The first specialized congress of urban administration and city councils.

-Khoshchehreh, Mohammad (2017). There is relationship among oil price and corruption: sale of crude oil is the peak point of all errors. Eqtesad Online website. Date of access: 19/08/2017.

-Rahimian, Narges (2014). Analysis on economic corruption and ways of fighting against it, Economic journal Vols. 9^\&10, December 2014 and January 2025. Pp. 103-116.

Rafipour, Faramarz (2007). Social cancer of corruption. Enteshar Joint Stock Company. 2007, ISBN: 3-196-325-964-978.

-Samani, Ali (2013). Review of effect of religious beliefs in prevention from administrative corruption, The second international conference on management, entrepreneurship and economic development.

-Tehrani, Farzaneh, Davani, Gholam Hossein (2015). The corruption root in the body of osctrich group. Etemad Newpapers Vol. 3321 p. 9 (Economy). Date of access: 20/08/2015.

-Tabibian, Mohammad (2016). The government should reduce public friction with administrative corruption system/ the single figure inflation rate should be followed by public welfare. ILNA News Agency, dated 29/06/2016. 
-Kashmiripour, Behzad (2015). Rent and rent-seeking: Trans-factional disease in Islamic Republic. Persian Deutsch Welle, date of access: 03/11/2014.

-Kashfi, Mansur. Bribery, corruption and change of contract: oil investment in Iran. Oil Price Website, date of access: 18/06/2016.

-Karimianm Maryam, Mohammad Poodinepir, \& Marjan Karimian Bostani (2014). The effect of geographic situation of frontier cities on administrative health. (Case study: Governmental departments in Sistan zone). National Conference on architecture, civil and urban environment.

-Giddens, Anthony (1998). Consequences of modernity. Transl. Mohsen Salasi. Tehran: Markaz Pub.

- Nikahang, Kosar (2016). The internalized financial corruption in religious structure of Iran. Khodnevis Website, date of access: $2^{\text {nd }}$ July 2016.

-Mehnatfar, Yousef (2008). Economic corruption and way of fighting against it in process of economic development. Pp. 1,3,4.

-Naghizdeh, Mohammad (2013). Development in Iran and Japan. Etemad Newspaper. Vol. 2828. Date of access: $18^{\text {th }}$ November 2013.

-Bourdieu, P. (1986), “The forms of Capital” in J. Richardson (ed.) Handbook of Theory and Research for Sociology of Education N. Y. Greenwood Press.

-DiPiazza, A. Samuel (2008), "Confronting Corruption", January.Goozner, Merrill (2014), TheFiscal Times, (www.thefiscaltimes.com/Articles/2011/12/13/TheTen-LargestGlobal-Business-Corruption-Cases), Accessed on November.

-Dimant, Eugen \& Tosato, Guglielmo(2017) "causes and effects of corruption: what has past decade's empirical research taught US? A SURVEY'Journal of Economic Surveys, Vol. 00, No. 0, pp. 1-22.

-Kim Mannemar Sønderskov \& Peter Thisted Dinesen(2017) anish Exceptionalism: Explaining the Unique Increase in Social Trust over the Past 30 Years.

-Kawaju wo shimei teishi e: Boueicho, heli dangou jiken uke" ("Kawasaki Heavy delisted by MOD, based on helicopter bid-rigging case"), Nihon Keizai Shimbun, July 29, 2013 http://www.nikkei.com/article/DGXNASDG2903U_Z20C13A7CR8000/) (in Japanese);

-Kawaju , kabunushi ga yakuin teiso seikyu: Rikuji heli dango, 46 oku songai” ("Kawasaki Heavy shareholders seek to sue management; GSDF helicopter bid-rigging, 4.6 billion in damages"), Kobe Shimbun, July 23, 2013 (http://www.kobe-np.co.jp/news/shakai/201307/0006185433.shtml) (in Japanese). 
-Kochi de kansei dango nintei: Kotorii, Kokukosho ni kaizen sochi youkyu" "Governmentled-

bid-rigging found in Kochi: JFTC demands improvements by MLIT"), Nihon Keizai Shimbun,

Oct. 17, 2012 (http://www.nikkei.com/article/DGXNASDG1703Y_X11C12A0CR8000/) (in

Japanese).

- Kochi de kansei dango nintei: Kotorii, Kokukosho ni kaizen sochi youkyu" ("Governmentled

bid-rigging found in Kochi: JFTC demands improvements by MLIT"), Nihon Keizai Shimbun,

Oct. 17, 2012 (http://www.nikkei.com/article/DGXNASDG1703Y_X11C12A0CR8000/) (in

Japanese).

-Lynden JL, Klingle W. Supervising organizational health. Supervision Journal. 2014; 4(2): 3-5.

Midha, Vishal, (2012). Impact of consumer empowerment on online trust, journal homepage.

-Latham \& Watkins ,Marunouchi Building, 32nd Floor, 2-4-1 Marunouchi, Chiyoda-ku, Tokyo 100-6332, Japan Tel: +81362127800 / Fax: +81 362127801 / URL: http://www.lw.com.

-OECD news release, "Serious Concerns Remain over Japan's Enforcement of Foreign Bribery

Law, Despite Some Positive Developments" (Jan. 12, 2012) (http://www.oecd.org/daf/anti).

-Park, Junyeon(2018) Bribery \& Corruption, Contributing Editors: Jonathan Pickworth \& Deborah Williams Published by Global Legal Group , First Edition.

-Partanen ,Anu. (2016). The Nordic Theory of Everything: In Search of a Better life. Harper publishing.

-Robbins, Blaine G. (2012). Institutional Quality and Generalized Trust: A Non-recursive Causal Model. Social Indicators Research, 107(2), 235-258.

-Segraves,Julie corruption.html,Accessed on April.Vaezoon.ir/Portal/Culture/Persian/Category ID/13360/CaseID/97522/71243.aspx (2012), Accessed on November.

-Yoshida, Daiske(2018) Bribery \& Corruption, Contributing Editors: Jonathan Pickworth \& Deborah Williams Published by Global Legal Group , First Edition.

www. Transparency.org

- ICC News Website, March 2018 